Article

\title{
Analysis of Pneumatic Pressure Vibration Affected by Connecting WCs and Discharge Load Types
}

\author{
Kazuya Fujimura * and Kyosuke Sakaue \\ Department of Architecture, School of Science and Technology, Meiji University, 1-1-1, Higashimita, Tama-ku, \\ Kawasaki 214-8571, Japan; sakaue@isc.meiji.ac.jp \\ * Correspondence: ce130622@gmail.com; Tel.: +81-(0)44-934-7380
}

Academic Editors: Ling Tim Wong and Kwok Wai Mui

Received: 7 February 2017; Accepted: 26 May 2017; Published: 29 May 2017

\begin{abstract}
In the design of a drainage system, allowable drainage flow quantity (drainage capability) is defined for each pipe diameter in order to prevent seal water from breaking. In Japan, SHASE-S 218 (Heating, Air-Conditioning, and Sanitary Standard) stipulates the evaluation standard for drainage capability. Regardless of the presence or absence of connection of the traps, there are two types of test criteria. One is that pressure in the pipe should fall within $\pm 400 \mathrm{~Pa}$, and the other is that the seal loss should be less than $25 \mathrm{~mm}$. Nevertheless, recent studies revealed that the connecting of traps attenuates pneumatic pressure in pipes and causes a tendency of the power spectrum distribution to change. This phenomenon may be attributable to the fact that seal water vibration is a response phenomenon to pneumatic pressure vibration, and that they affect each other. In view of this, we conducted discharge experiments based on SHASE-S 218 with and without traps (including water-saving toilet bowl (hereinafter, referred to as "WC") using a real size drainage experimental system to clarify how the connection of WC might influence pneumatic pressure. We revealed that as the number of toilets connected to the drainage system increases, the pneumatic pressure and seal water loss decrease.
\end{abstract}

Keywords: drainage system; trap; induced siphonage; vibration reply phenomena

\section{Introduction}

Many studies have been conducted in various countries to predict the pressure generated inside pipes in order to evaluate the performance of water supply and drainage systems [1]. In Japan, SHASE-S 218 [2-4] (Heating, Air-Conditioning, and Sanitary Standard) stipulates the test method for the drainage capability of drainage stack systems. The judging criteria consists of the following two conditions: that the allowable pressure (the pneumatic pressure or pressure referred in the article indicates the airflow pressure) in a pipe should fall within $\pm 400 \mathrm{~Pa}$, and that the seal loss should be less than $25 \mathrm{~mm}$. Although discharge from fixtures with varying flow rates occurs in actual drainage systems, constant discharge has been the standard discharge mode used in testing to circumvent the problem of selecting a representative fixture for testing. However, there have only been a few quantitative comparisons [5-9] of pressure vibration in pipe and seal loss in water-saving sanitary fixtures widely used today and in constant discharge in test conditions, and therefore drainage capability may not have been properly evaluated.

In view of this, we conducted discharge experiments in a real-scale drainage tower to analyze pressure vibration in pipes and seal water fluctuations, and clarified the effect of a WC connection on pressure vibrations in pipes, as well as the relationship between pressure and seal loss as they occur in constant discharge and fixture discharge. 


\section{Outline of Real-Scale Drainage Tower Experiment}

\subsection{Purpose}

Experiments were conducted to collect data of pressure vibrations in pipes in horizontal branch drainages on each floor, as well as seal water fluctuations and residual seal depths in various test traps when a constant discharge load based on SHASE-S218 was applied.

\subsection{Experimental Drainage System}

The outline of the experimental drainage system is shown in Figure 1; dates of experiments and weather conditions are shown in Table 1; and the specification of measurement devices is given in Table 2. The system used in the experiments is a special fitting drainage system equivalent to a fifteen-story building. Test WCs were installed either on each floor between the 2nd and 12th floors, or on $2 \mathrm{nd}, 7 \mathrm{th}$, and 11th floors. When a WC was used in combination with a contrary bell trap, the trap was placed on the 8th floor and the WC on the 9th.

Caps made of Polyvinyl chloride (hereinafter, referred to as "PVC caps") were placed at the ends of horizontal branch drainage on the floors where no traps were connected. Discharge load was made from the 13th to 15th floors, and load variations were made in terms of load type and flow rate.

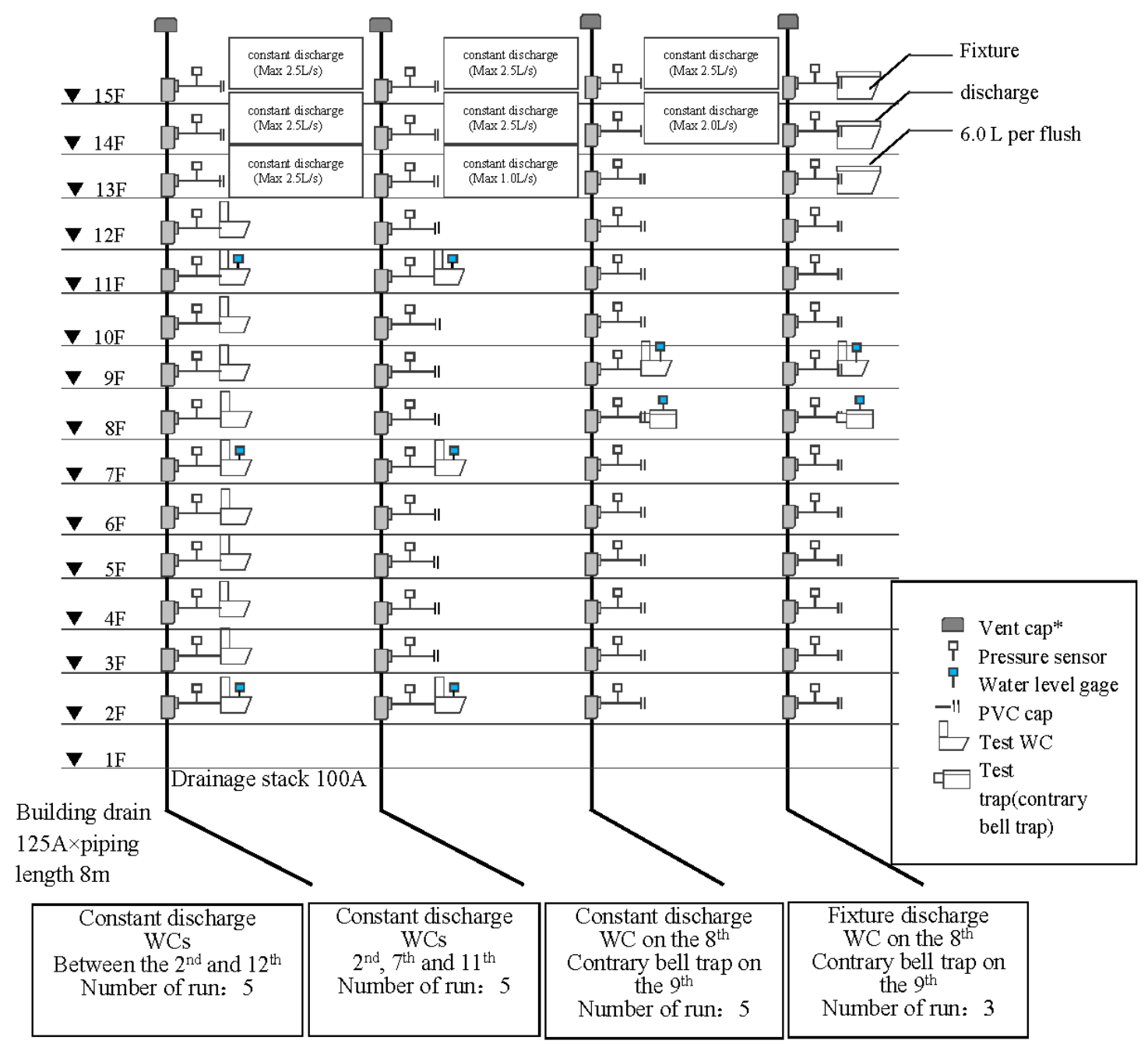

*Effective opening area: $8717.2 \mathrm{~mm}^{2}$ Ventilation resistance: $6.0 \mathrm{~m}$

Figure 1. Outline of the experimental drainage system. 
Table 1. Dates of experiments and weather conditions.

\begin{tabular}{cccc}
\hline \multirow{2}{*}{ Experiment Condition } & \multicolumn{2}{c}{ WCs } & \multirow{2}{*}{ WC Contrary Bell Trap } \\
\cline { 2 - 3 } & Between the 2nd and 12th & 2nd, 7th, and 11th & \\
\hline Dates of experiments & 14 September 2015 & 7 November 2013 & 15 September 2015 \\
Weather conditions & Cloudy & Cloudy & Cloudy \\
\hline
\end{tabular}

Table 2. Specifications of measurement devices.

\begin{tabular}{cccc}
\hline Device & Type & Range & Non-Linearity [within \% F.S.] \\
\hline Pressure sensor & Gauge pressure transducer & $-1.0 \times 10^{4}$ to $+1.0 \times 10^{4} \mathrm{~Pa}$ & \pm 0.4 \\
Water sensor & Electrostatic capacitance level gauges & $0-200 \mathrm{~mm}$ & \pm 0.3 \\
\hline
\end{tabular}

\subsection{Measuring Conditions}

Based on SHASE-S218, constant discharge loads $(1.5 \mathrm{~L} / \mathrm{s}, 3.0 \mathrm{~L} / \mathrm{s}, 4.0 \mathrm{~L} / \mathrm{s}, 4.5 \mathrm{~L} / \mathrm{s}, 6.0 \mathrm{~L} / \mathrm{s})$ and fixture discharge loads from one to three WCs were applied. Discharge was made $5 \mathrm{~s}$ after measuring commenced. Pressure vibrations in pipes, seal water fluctuations, and residual seal depths were measured at a sampling cycle of $20 \mathrm{~m} / \mathrm{s}(50 \mathrm{~Hz})$ without low-pass filters. Measurements were made for one minute after the target flow rate was reached in constant discharge, and for $40 \mathrm{~s}$ in fixture discharge. In both conditions discharging started $5 \mathrm{~s}$ after the beginning of measurement.

\subsection{Test WC and Test Trap}

The cross-sectional views of a test trap with a water level sensor and a test WC are shown in Figure 2; their basic parameters are given in Table 3. A siphonic drainage type WC with $6.0 \mathrm{~L}$ per flush was used as the test WC. All traps were filled as default.

Table 3. Basic parameters of test traps.

\begin{tabular}{cccccc}
\hline Test WC & Seal Depth & Seal Water & $\begin{array}{c}\text { Ratio of Leg's } \\
\text { Cross-Sectional Area [-] }\end{array}$ & $\begin{array}{c}\text { Characteristic } \\
\text { Frequency [Hz] }\end{array}$ & $\begin{array}{c}\text { Average Drainage } \\
\text { Rate of Fixture [L/s] }\end{array}$ \\
\hline Test Trap & {$[\mathrm{mm}]$} & {$[\mathrm{mL}]$} & 1 & 2.34 & - \\
Contrary bell trap & 50 & 330 & 0.16 & $1.27,2.47$ & 2.2 \\
WC A & 58 & 2400 & & \\
\hline
\end{tabular}

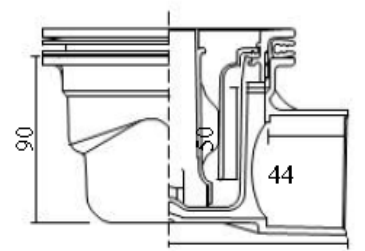

100

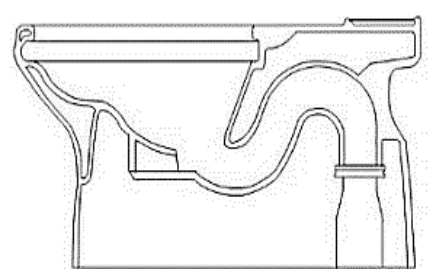

WC A $[\mathrm{mm}]$

Contrary bell trap

Figure 2. Cross-sectional views of a test trap and a test WC A.

\section{Effects of Load Type on Pressure Vibrations in Pipes and Seal Water Fluctuations}

\subsection{Purpose}

Fluctuation wave patterns were analyzed to clarify the pressure vibrations in pipes for each load type and the characteristics of seal water fluctuation. 


\subsection{Method of Analysis}

The wave patterns of pressure vibrations in pipes and seal water fluctuation were compared for each load type. Standard deviations (SD) were calculated and the pressure vibrations in the pipes and the seal water fluctuation were quantitatively compared.

\subsection{Results}

\subsubsection{Constant Discharge Load}

Figure 3 shows the representative wave patterns of the pressure vibrations and seal water fluctuations when WCs were placed on all the floors and on only three floors. Figure 4 illustrates the $\mathrm{SD}$ of seal water fluctuation when the fixed flow rate load was $4.0 \mathrm{~L} / \mathrm{s}$. Figure 5 shows the power spectrum density distribution of pneumatic pressure vibration by the constant discharge load $(4.0 \mathrm{~L} / \mathrm{s})$.

The ranges of seal water fluctuation wave patterns for each discharge type increased as the discharging floor decreased. This can be clearly seen in Figure 4. The SDs of seal water fluctuation on the 2nd floor for both all-floor WC placement and three-floor placement were approximately 2.5 times larger than those on the 11th floor. This can be attributed to the fact that the pressure vibration in the pipes on the lower floors mainly consisted of positive pressure as opposed to those on the higher floors that consisted of negative pressure.

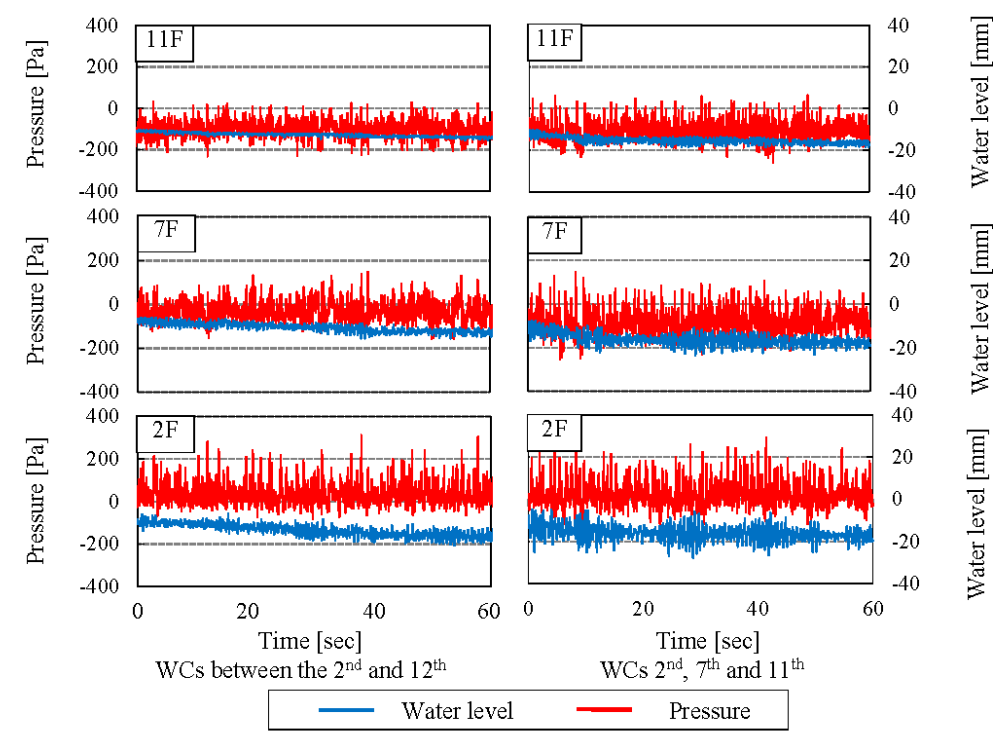

Figure 3. Examples of pressure fluctuation wave patterns and seal water fluctuation wave patterns $(4.0 \mathrm{~L} / \mathrm{s})$.

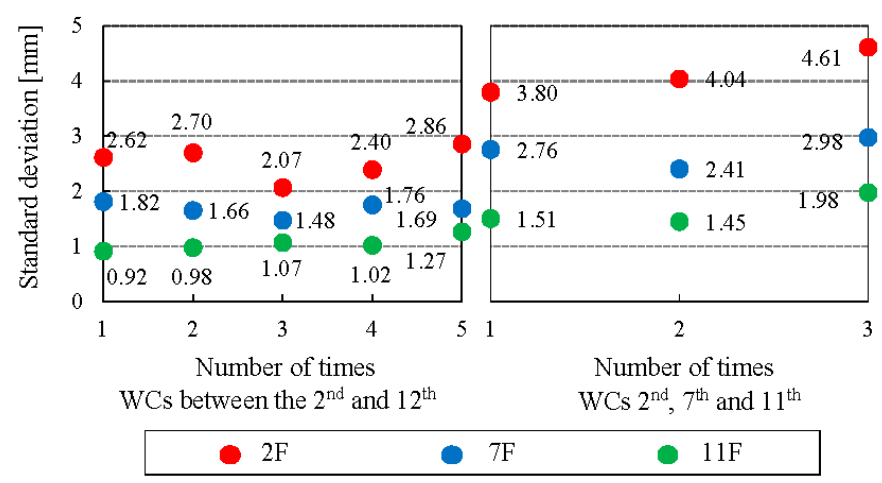

Figure 4. Illustration of the SDs of seal water fluctuation $(4.0 \mathrm{~L} / \mathrm{s})$. 

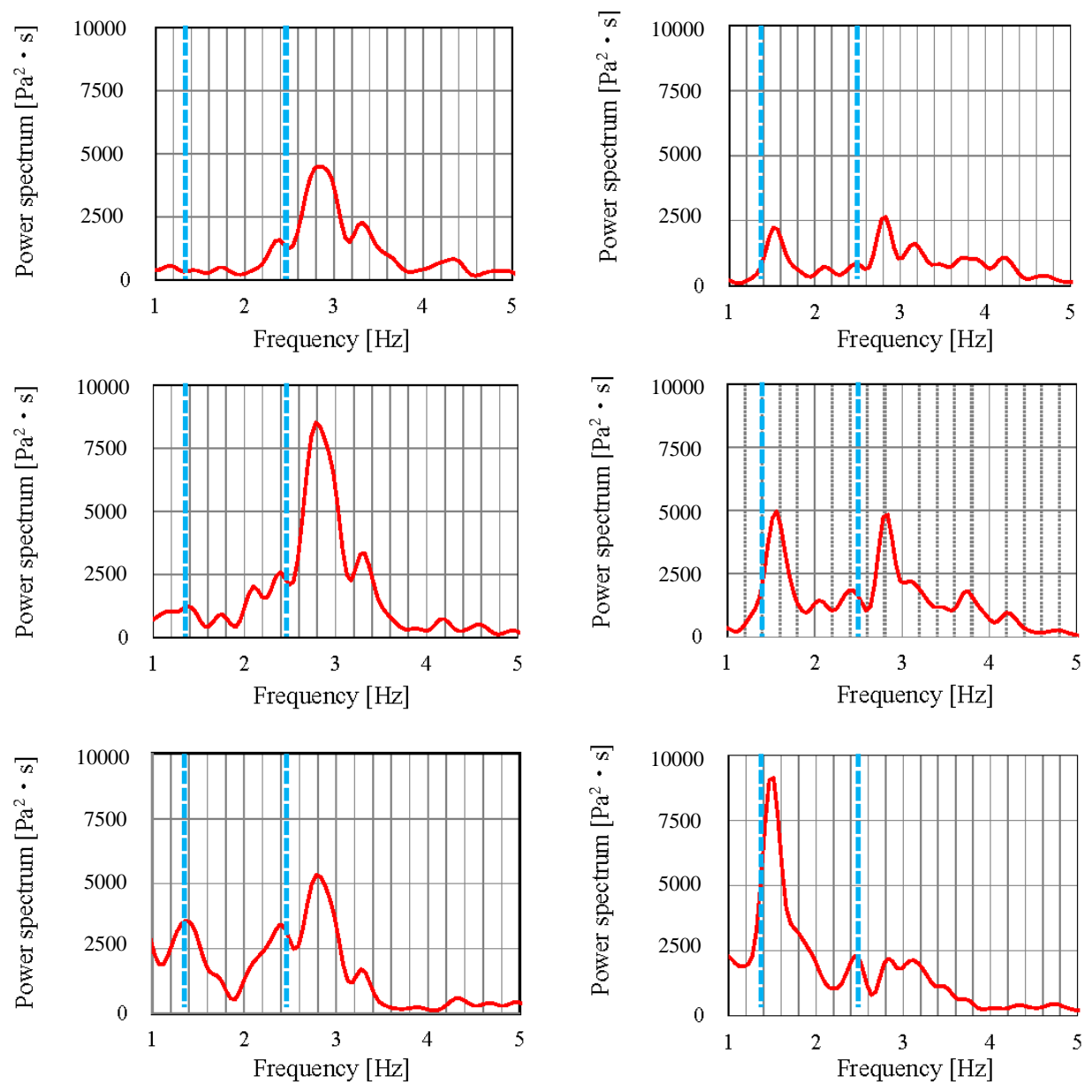

WCs between the $2^{\text {nd }}$ and $12^{\text {th }}$

WCs $2^{\text {nd }}, 7^{\text {th }}$ and $11^{\text {th }}$

Power spectrum distribution $\quad-=-$ Characteristic frequency (test WC)

Figure 5. An example of the power spectrum density distribution.

Figure 4 also indicates that the range of the seal water fluctuation wave patterns in the all-floor WC placement was smaller than that in the three-floor placement. It can be assumed that in the all-floor placement, the seal water on each floor had an influence on the pressure vibration in the pipes, and as a result the pressure in the pipes was reduced near the floors where traps were connected.

Figure 5 also indicates that the power spectral density distribution of the pressure fluctuation was larger in the case of installing test WCs on three floors (2nd, 7th, 11th) than in the case of installing test WCs through the whole building (between 2nd and 12th). Many pressure components of the frequency were close to the natural frequency of the test toilet. Therefore, the partial resonance phenomenon seems to have increased the seal water fluctuation in the case of installing WCs on three floors compared to the case of installing toilets on every floor in the building.

\subsubsection{Fixture Discharge Load}

Figure 6 shows some examples of the wave patterns of pressure vibration in pipes and seal water fluctuation. The wave patterns of the seal water fluctuation corresponded with the pressure vibration as the seal water fluctuated in response to the pressure in the pipes; when the maximum pressure was produced right before discharged water passed through, then seal loss occurred. Seal water in a contrary bell trap had a larger range of fluctuation than that in a WC. 

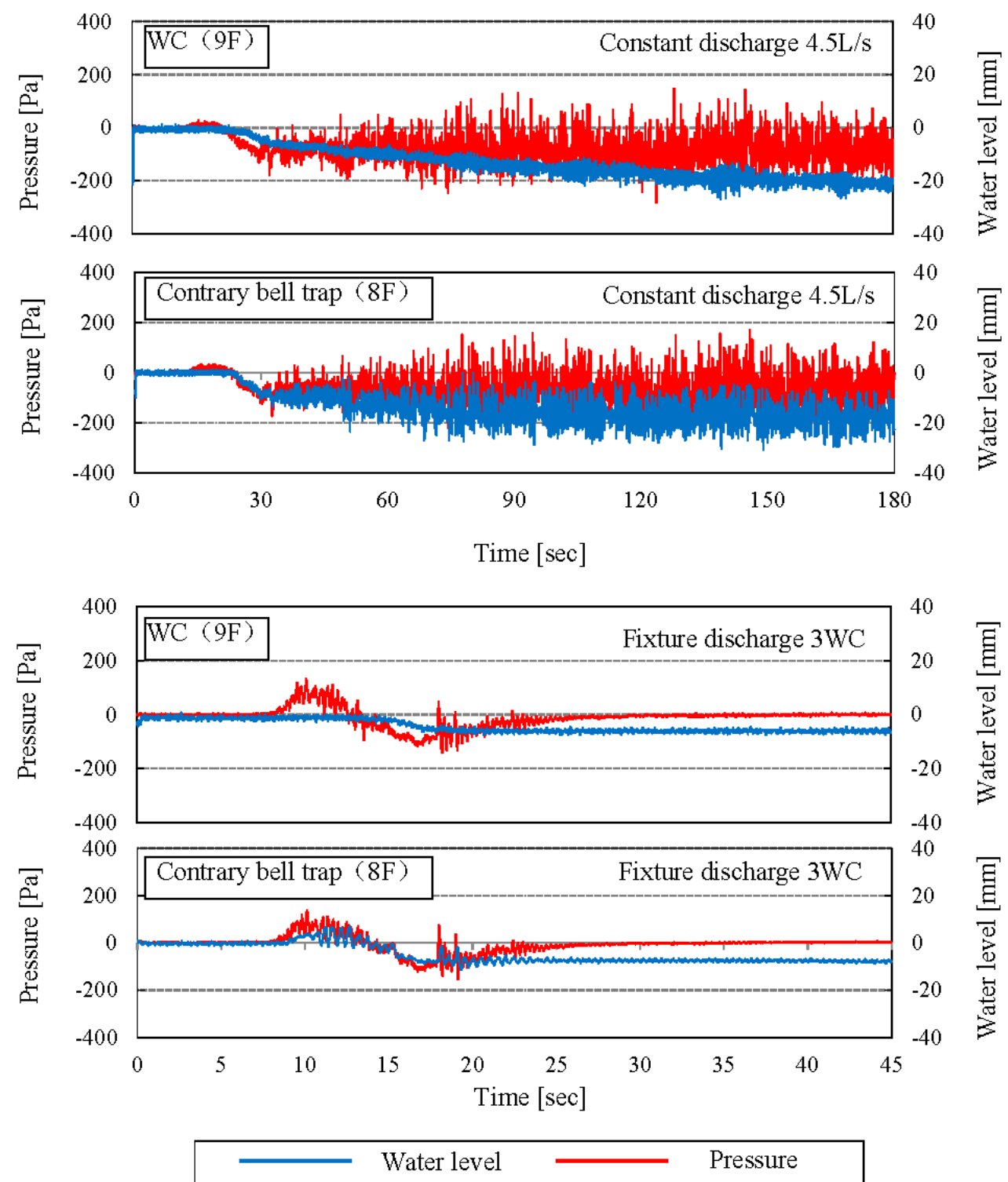

Figure 6. Examples of the wave patterns of pressure vibration in pipes and seal water fluctuation.

\subsubsection{Comparison between Constant Discharge Load and Fixture Discharge Load}

The SD of the seal water fluctuation is shown in Figure 7. Seal water fluctuation wave patterns differed greatly depending on the load type. Figure 7 clearly shows this, as the SD of the seal water fluctuation in the contrary bell trap was two to three times larger than that in the WC. The structure and water seal of the trap may have been the cause of the difference in the seal water fluctuation among traps.

The scatter diagrams of the SDs of the pressure vibration in the pipes and the seal water fluctuation, in addition to their primary regression equations, are shown in Figure 8. The regression coefficient $a$ and the ratio of regression coefficient of the constant discharge to the fixture discharge $\alpha$ are shown in Table 3. From Figure 8, it was found that there is a high correlation between the SD of the pressure vibration in the pipes and the SD of the seal water fluctuation, as the determination coefficient $\mathrm{R}^{2}$ was 0.979-0.996, which is quite high for both constant discharge and fixture discharge. By comparing these regression coefficients, it is possible to quantitatively evaluate the influence of the fixture drainage load on seal water relative to the constant discharge load.The ratio of regression coefficient $\alpha$ was 0.97 for the contrary bell trap on the 8th floor and 1.47 for the WC on the 9th floor (Table 4). 


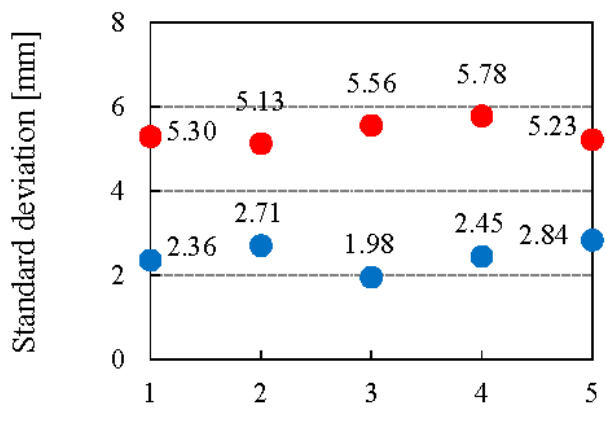

Number of times

Constant discharge $4.5 \mathrm{~L} / \mathrm{s}$

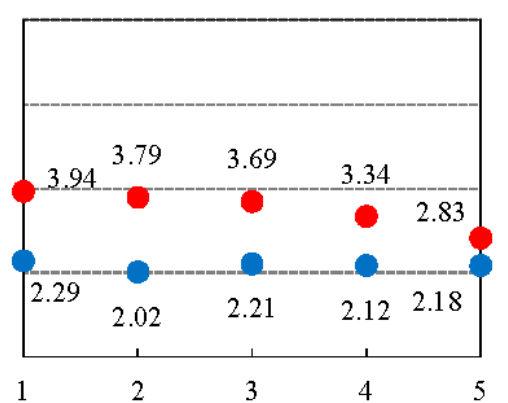

Number of times

Fixture discharge $3 \mathrm{WC}$

Contrary bell trap ( $8 \mathrm{~F})$

WC (9F)

Figure 7. SD of seal water fluctuation.
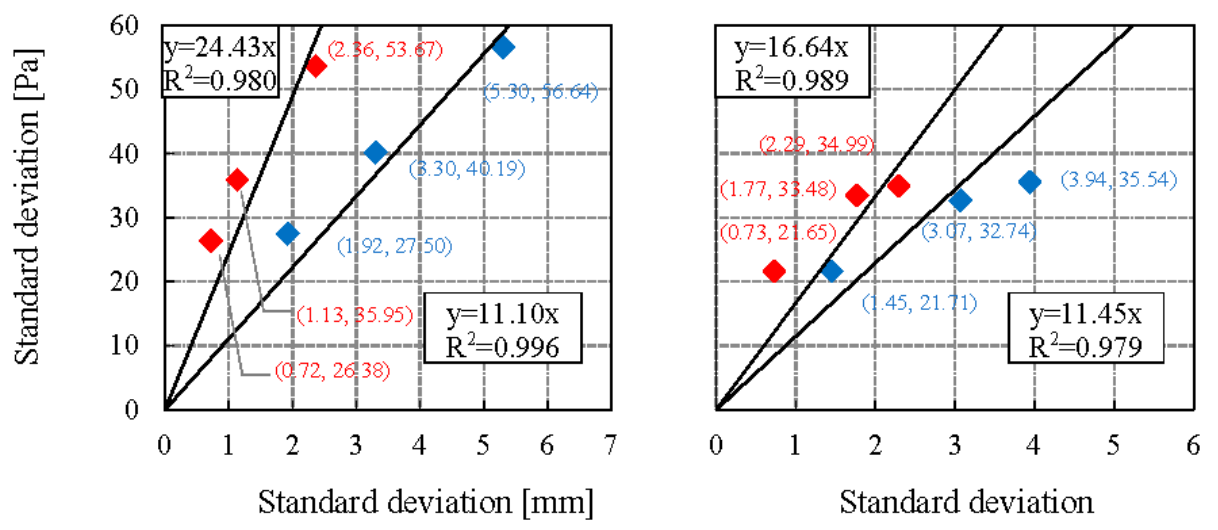

Constant discharge

Fixture discharge

Contrary bell trap $(8 \mathrm{~F})$

WC (9F)

Figure 8. Scatter diagrams of the SDs of the pressure vibration in pipes and seal water fluctuation, as well as their primary regression equations.

Table 4. Regression coefficient $a$ and the ratio of regression coefficient of the constant discharge to the fixture discharge.

\begin{tabular}{cccc}
\hline \multirow{2}{*}{ Floor } & \multicolumn{2}{c}{ Regression Coefficient $(\boldsymbol{a})$} & \multirow{2}{*}{ Ratio of Regression Coefficient $(\boldsymbol{\alpha})$} \\
\cline { 2 - 3 } & Constant Discharge & Fixture Discharge & \\
\hline 8 (Contrary bell trap) & 11.10 & 11.45 & 0.97 \\
9 (WC) & 24.43 & 16.64 & 1.47 \\
\hline
\end{tabular}

\section{Effects of Load Type on Pressure in Pipe and Seal Loss}

\subsection{Purpose}

We conducted experiments in a real-scale drainage tower and analyzed the pressure in pipes and the seal loss to clarify the relationship between discharge type and seal loss on each floor according to the number of WCs installed, and to quantitatively compare the pressure in pipes and the seal loss between fixture discharge load and constant discharge load. 


\subsection{Method}

Seal losses in each type of discharge and load were compared. The correlation of the seal loss of a trap with minimum pressure on the floors where traps were placed was also examined.

\subsection{Results}

\subsubsection{Constant Discharge Load}

The relationship of the seal loss on each floor in each type of discharge is shown in Figure 9. In a constant discharge of $4.0 \mathrm{~L} / \mathrm{s}$, the seal loss was largest on the 2 nd floor and smallest on the 11th floor. This may be explained by the fact that positive pressures dominated on the 2nd floor and, as seen in Figure 3, that seal loss from locally-produced positive pressures of 300 Pa overrode seal loss produced by negative pressures. In a constant discharge of $6.0 \mathrm{~L} / \mathrm{s}$, seal losses tended to be roughly equal on the $2 \mathrm{nd}, 7 \mathrm{th}$, and 11 th floors. This seems to have been caused by the comparable negative pressure produced on these floors when the discharge flow rate was $6.0 \mathrm{~L} / \mathrm{s}$.

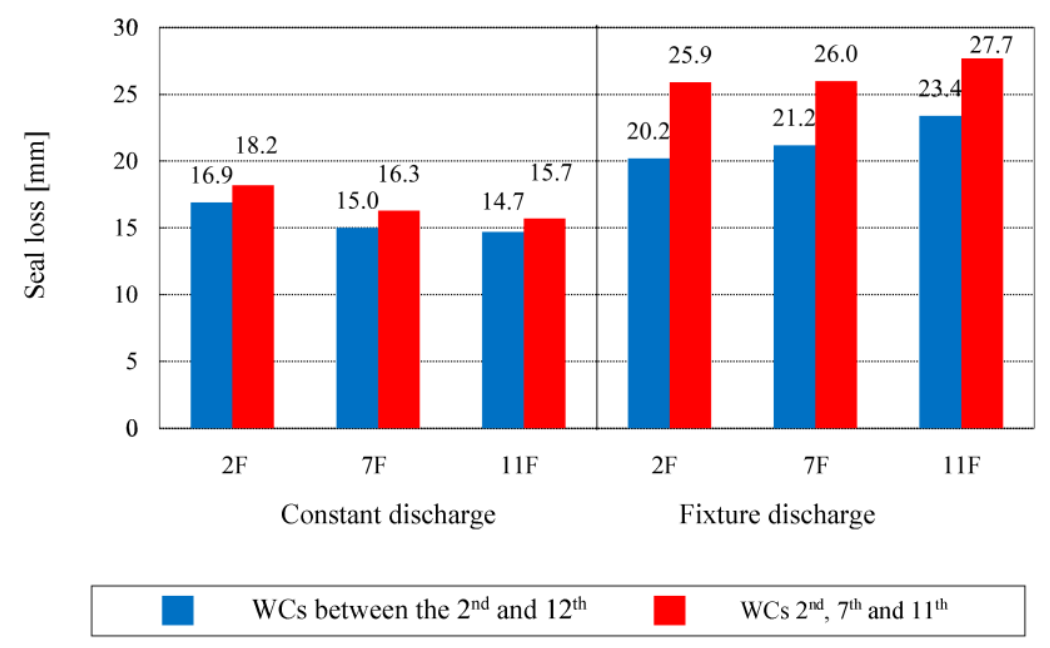

Figure 9. Relationship of seal loss on each floor in each type of discharge.

\subsubsection{Comparison of Constant Discharge Load and Fixture Discharge Load}

Seal loss on each floor for each discharge type is shown Figure 10. For both the contrary bell trap and WC, seal loss in constant discharge was larger than that in fixture discharge. The scatter diagram and primary regression equation for the minimum pressure in the pipe and the seal loss in each load type are shown in Figure 11. The regression coefficient $a$ and the ratio of regression coefficient of the constant discharge to the fixture discharge $\alpha$ are shown in Table 5. Figure 11 shows the determination coefficient.

$\mathrm{R}^{2}$ was high (0.72-0.92), indicating a high correlation between the minimum pressure in the pipe and the seal loss. In Table 5, the ratios of regression coefficient for the contrary bell trap (8th floor) and WC (9th floor) were 1.63 and 1.98, respectively. From this, it can be expected that the seal loss in a contrary bell trap would be about 1.6 times, and that in a WC is about twice as large in constant discharge as in fixture discharge, given a similar level of negative pressure. Also, there seems to be a significant difference in the ratio of regression coefficient $\alpha$ among the test traps. 


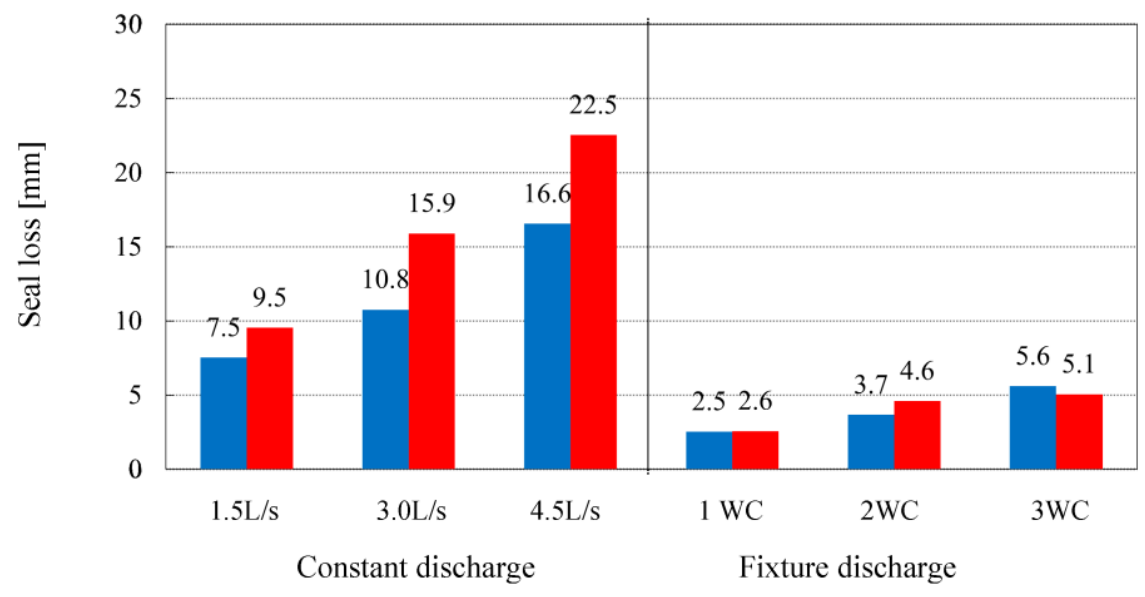

WCs between the $2^{\text {nd }}$ and $12^{\text {th }} \quad$ WCs $2^{\text {nd }}, 7^{\text {th }}$ and $11^{\text {th }}$

Figure 10. Seal loss on each floor for each discharge type.
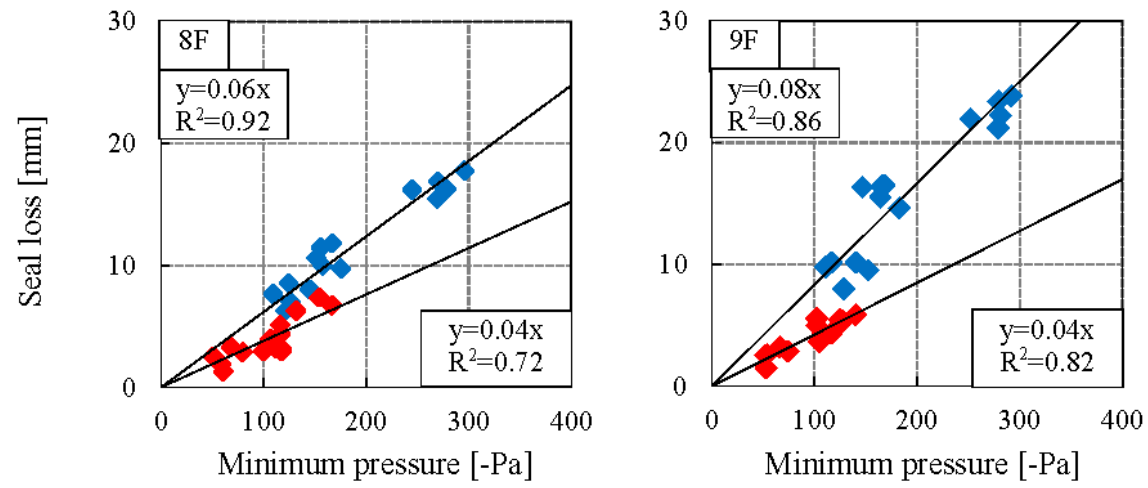

Contrary bell trap (8F)

WC $(9 F)$

Figure 11. The scatter diagram and primary regression equation for the minimum pressure in the pipe and the seal loss in each load type.

Table 5. Regression coefficient $a$ and the ratio of regression coefficient of the constant discharge to the fixture discharge $\alpha$.

\begin{tabular}{cccc}
\hline \multirow{2}{*}{ Floor } & \multicolumn{2}{c}{ Regression Coefficient $(a)$} & \multirow{2}{*}{ Ratio of Regression Coefficient $(\boldsymbol{\alpha})$} \\
\cline { 2 - 3 } & Constant Discharge & Fixture Discharge & \\
\hline 8 (Contrary bell trap) & 0.062 & 0.038 & 1.63 \\
9 (WC) & 0.083 & 0.042 & 1.98 \\
\hline
\end{tabular}

\section{Conclusions}

In this study, the pressure vibration in pipes and the seal water fluctuation data collected in real-scale drainage tower experiments were analyzed. The results can be summarized as follows:

(1) The greater the number of WCs installed, the less likely the occurrence of seal loss. The factor here seems to be the water seal of traps that are connected.

(2) The range of seal water fluctuation wave patterns tended to be larger on the lower floors than on the higher floors. 
(3) Seal loss in a contrary bell trap is approximately 1.5-2 times larger in constant discharge than in fixture discharge. However, no significant differences in seal loss due to load type were observed in a WC.

In this research, in order to improve the evaluation method of the drainage system stipulated in Japan more properly, various experiments are carried out and the existing knowledge is expanded upon.

The problem of reducing seal loss and seal water fluctuation SDs with increasing water seal is yet to be resolved in the future. We also need to give consideration to the method of evaluating the effects of seal loss on pressure vibration in pipes.

Author Contributions: Kyosuke Sakaue conceived and planned the research/ measurement; Kazuya Fujimura carried out the experiment, analyzed the data and wrote the paper.

Conflicts of Interest: The authors declare no conflict of interest.

\section{References}

1. Apollonio, C.; Balacco, G.; Fontana, N.; Giugni, M.; Marini, G.; Piccinni, A.F. Hydraulic Transients Caused by Air Expulsion during Rapid Filling of Undulating Pipelines. Water 2016, 8, 25. [CrossRef]

2. The Society of Heating, Air-Conditioning and Sanitary Engineers of Japan. SHASE-S 218-2014, "Testing Methods of Flow Capacity for Drainage System in Apartment Houses"; The Society of Heating, Air-Conditioning and Sanitary Engineers of Japan: Tokyo, Japan, 2014.

3. Sakaue, K.; Kamata, M.; Ohtsuka, M.; Saitoh, H.; Tsukishima, K. The Method of Test for Capacity of Drainage System. In Proceedings of the CIB W062 International Symposium, Washington, DC, USA, 1992; pp. $231-244$.

4. Sakaue, K.; Kamata, M.; Zhang, Y. A Study on the Test Method of Trap Performance. In Proceedings of the CIB W062 International Symposium, Brno, Czech, 19-21 September 2007; pp. 321-332.

5. Fujimura, K.; Sakaue, K.; Toyama, T.; Kuriyama, H.; Mitsunaga, T. Evaluation Method for Pressure in Pipes against Trap Seal Loss Part 1-Analysis of Effects of Pressure Waveform on Seal Water; The Society of Heating, Air-Conditioning and Sanitary Engineers of Japan: Tokyo, Japan, 2013; pp. 1-8.

6. Fujimura, K.; Sakaue, K.; Toyama, T. Analysis of influence of connection of traps on pneumatic pressure in stack pipe. In Proceedings of the CIB W062 International Symposium, Nagano, Japan, 17-20 September 2013; pp. 143-154.

7. Takahashi, M.; Sakaue, K.; Toyama, T.; Fujimura, K. Characteristics of pressure in test drainage system with traps for flow capacity. In Proceedings of the CIB W062 International Symposium, Sao Paulo, Brazil, 8-10 September 2014; pp. 199-210.

8. Fujimura, K.; Sakaue, K.; Takahashi, M.; Uemura, N.; Kuriyama, H. “The Influence of Pressure Caused by Equipment Drainage Load on Trap Seal Water", Technical Papers of Annual Meeting; The Society of Heating, Air-Conditioning and Sanitary Engineers of Japan: Tokyo, Japan, 2014; pp. 129-132.

9. Fujimura, K.; Sakaue, K.; Toyama, T.; Kuriyama, H.; Mitsunaga, T. Influence of Type of Discharge Load on Pressure Vibration in Pipes and Seal Water Vibration. In Proceedings of the CIB W062 International Symposium, Beijing, China, 17-20 August 2015; pp. 112-122. 